Pepijn van Houwelingen

The Netherlands Institute for Social Research

\section{Paul Dekker}

The Netherlands Institute for Social Research

\title{
SATISFACTION WITH DEMOCRACY IN PERSPECTIVE: ANCHORING TODAY BY LOOKING BACK AND FORWARD
}

DOI: $10.2478 /$ ppsr-2021-0002

\begin{abstract}
Authors
Pepijn van Houwelingen $(\mathrm{PhD})$ was a researcher at The Netherlands Institute for Social Research and is now a member of the Dutch Parliament. He studied Industrial Engineering and Management at Twente University and is involved in research concerning democracy and (political) participation.
\end{abstract}

ORCID no. 0000-0002-7147-4719

e-mail: p.vhouwelingen@tweedekamer.nl

Paul Dekker $(\mathrm{PhD})$ was a senior researcher at The Netherlands Institute for Social Research and is a professor at Tilburg University.

ORCID no. 0000-0002-8054-4184

e-mail: paul.dekker@tilburguniversity.edu

\begin{abstract}
The question of how satisfied people are with the workings of their national democracy has often been criticized but is still the international standard measurement of satisfaction with democracy (SWD). In this paper we explore the benefits of adding questions about remembered and expected satisfaction 'ten years ago' and 'ten years from now', as were asked in the ISSP citizenship surveys of 2004 and 2014. Based on the data from seventeen European countries, we find that national samples:

- do not show universal 'nostalgia',

- produce good guesses of past satisfaction but show no futurist insights,

- give retrospective judgments that do not correlate well with changes in expert opinions,

- give retrospective judgments that do not correlate well with changes in the share of the populist vote.

At the individual level we find:

- that in almost all countries expected satisfaction with democracy ten years from now is a better predictor of political trust and feelings of political efficacy than satisfaction with democracy today,

- that in almost all countries expected satisfaction with democracy ten years from now is a better predictor of the preference for populist voting (in one national case study),

- we note that Poland is the only country in our sample where citizens were, in 2014, retrospectively more positive about the development of their democracy, probably due to the severe economic conditions Poland faced in 2004.

Overall, we do not find evidence for the relevance of retrospective judgements, but some evidence for the relevance of prospective judgements. We recommend further research into individual changes in present satisfaction and perceptions of these changes to better understand the frames of reference of 'satisfaction with democracy today'.
\end{abstract}

Keywords: satisfaction with democracy, Europe, Cantril, retrospection, prospection 


\section{Satisfaction with democracy today}

The question '...on the whole, how satisfied are you with the way democracy works in [your country]?' is worldwide the core, and often only, question to measure satisfaction with democracy (SWD). SWD might as such be a theoretical concept (Norris, 1999, Clarke, Dutt and Kornberg, 1993, Dahlberg and Holmberg, 2014, Christmann, 2018), or it is used for concepts such as 'democratic responsiveness' (Ceron and Memoli, 2016; Morlino and Quaranta, 2014), and 'perceived effectiveness of a regime' (Lagos, 2003)'. The indicator has been disputed (Anderson, 2002; Canache, Mondak and Seligson, 2001; Linde and Ekman, 2003; Quarantana, 2018), but has nevertheless been accepted widely as common measure for 'the level of support for the way the democratic regime works in practice' (Linde and Ekman, 2003), and has survived in recent tests with alternative measurements as 'a decent proxy to measure the citizens' evaluations of democracy' (Quaranta, 2018; cf. Foa et al., 2020).

In this paper we will not go into the debate about the object of measurement when people are asked about (the functioning of) 'democracy', but focus on the points of reference or comparison, the anchors, of expressions of (dis)satisfaction. A basic problem when comparing 'satisfaction with democracy', both between individuals and at an aggregated level between countries, is the lack of a common (objective) anchor point. One person's score of 7 might be another person's 6 or 8 . There might be labels for the extreme scores, but they might have different meanings for respondents. There is no absolute point of reference and people might use different perspectives of comparison. One respondent might feel quite satisfied with democracy in his or her country 'compared to other countries' while another respondent might feel exactly the same but nevertheless give a lower score because he or she is not making a comparison with 'other countries' but with a 'better past'. In fact, in an earlier study (Van Houwelingen, Dekker \& Den Ridder, 2012), we asked Dutch respondents in a panel study explicitly to make a comparison with the past ('one year ago') when evaluating their satisfaction with Dutch (national) politics. These evaluations quite often differed from the evaluations given by the same respondents without an explicit point of comparison at the same two different points in time. In our study we were able to discuss this apparent paradox with respondents themselves. In general, they clearly indicated a preference for their own, usually more pessimistic, retrospective evaluations of democracy, even though this was often not consistent with the 'grades' they had given for their current satisfaction during past surveys that implied a more positive retrospective evaluation. For example, a typical respondent could give the same grade each year for his satisfaction with politics at that moment, but would at the same time indicate, retrospectively, that, nonetheless, 'politics was heading in the wrong direction last year'. If asked to choose between these two inconsistent evaluations respondents would almost always choose the more pessimistic retrospective evaluations.

Against this background we are interested in SWD-questions asked in the International Social Survey Programme (ISSP) citizenship modules of 2004 and 2014. A question about SWD at present was complemented in these modules with questions about the past and future: ${ }^{1}$

1 We have not been able to find the arguments of the ISSP researchers of 2004 to do so; the only arguments of the 2014 researchers to keep the questions is that the retrospective question might be interesting after ten years and the prospective question might be reconsidered because it 
- On the whole, on a scale of 0 to 10 where 0 is very poorly and 10 is very well: How well does democracy work in (COUNTRY) today?

- And what about 10 years ago? How well did democracy work in (COUNTRY) then?

- And how about 10 years from now? How well do you think democracy will work in (COUNTRY) then?

The questions resemble the often used 'Cantril-ladders' to measure life satisfaction. ${ }^{2} \mathrm{We}$ are investigating whether the addition of a time perspective might help to get a better idea of how collectives and individuals experience and evaluate democracy, and how these retrospective evaluations and prospective expectations of democracy are related to political attitudes and voting behaviour of individuals. As far as we know the additional questions have been used in a published work only once, by Ariely (2013). ${ }^{3}$

Retrospective survey questions are often used in the social sciences as 'second best' alternatives compared to panel data (Finney, 1981), due to different kinds of (cognitive) distortions such as 'telescoping', or cognitive dissonance (Golden, 1992; cf. Beckett et al., 2001). Studies concerning the reliability of retrospective survey questions have focused mostly on a relatively short period of up to one year (Smith, 1984), and on individual (instead of aggregated) reliability, usually based on panel data. Examples are voter recall studies (Schwarz and Oyserman, 2001; Van Elsas, Lubbe, Van der Meer and Van der Brug, 2013). Studies testing the aggregated - i.e., country level - and long-term accuracy ${ }^{4}$ of retrospective studies are rare. Studies with regard to prospective accuracy are, as far as we could ascertain, even rarer. The ISSP 2004 and 2014 citizenship modules, together, allow us, at the aggregated country level to measure the accuracy over a longer term (ten years) of both retrospective and prospective (attitudinal) SWD survey questions. The data also allows us to investigate the relevance of such a retrospective and prospective outlook for measuring satisfaction with democracy. We believe this is a potentially important contribution, because recent literature points to the value of including retrospective and prospective evaluations for explaining, for example, societal pessimism, and populism (Steenvoorden and Harteveld, 2018). In recent literature 'nostalgia', especially, has been connected to populism in general and the vote for Brexit and the election of Trump - whose slogan is 'Make America Great Again' - in particular (Kenny, 2017). Norris and Inglehart (2019) for example argue that longterm cultural value change and processes such as immigration and urbanization associated with these changes have, especially with older people, culmi-

had a higher number of missing answers in 2004 (Pammett 2016).

2 Known as self-anchoring scales, referring to the subjective labels ('the best possible life for you'/'the worst possible life for you') at both ends of the scale (Kilpatrick and Cantril 1960). The anchors in this paper do not refer to this but to the anchoring of judgments of the present situation between remembered satisfaction in the past and expected satisfaction in the future.

3 Without further reflections, Ariely combines the answers to the 'SWD today' and 'SWD ten years from now' questions in ISSP 2004 to measure SWD. A reliability analysis of the 2014 data confirms that this selection of 2 generates the highest Cronbach's alpha in 12 of the 17 European countries of this paper as well (in the Czech Republic, Norway, Slovenia and Sweden, a scale of all three items is marginally better, and in Switzerland the combination of today and ten years ago is more reliable).

4 We are, of course, aware that 'countries' do not make predictions and that our respondents, since the ISSP is not a panel study, have changed between the 2004 and 2014 waves. Moreover, because all our SWD measurements are based on perceptions and 'factual' SWD measurements do not exist it would, strictly speaking, be better to use the term 'correlation' instead of 'accuracy'. However, this would, we believe, make the text more difficult to read therefore we use the term 'accuracy' but with these disclaimers in mind. 
nated in a 'cultural backlash' because people feel they have become 'strangers in their own land' (Hochschild, 2016).

Moreover, according to economic voting theory, the importance of economic retrospective evaluations and prospective expectations - i.e., has the economy improved in the past and will it improve in the future or not? - in voting behavior is well recognized (Lacy and Christenson, 2017). Therefore, are retrospective evaluations and prospective expectations with regard to the functioning of democracy (instead of the economy) perhaps also possible important determinants with regard to, for example, voting behavior? Are those who have become less satisfied with democracy (irrespective of their satisfaction with democracy today), for example, perhaps more likely to vote for populist parties or to distrust politicians? In other words, should a 'democratic voting theory', not only include 'satisfaction with democracy today', but also incorporate a respondent's retrospective evaluation and prospective expectation of his or her satisfaction with democracy? In this paper we will try to answer this question from different perspectives.

We will use the data of the 17 European countries included in both the 2004 and 2014 ISSP datasets. This is a selection of liberal democracies that experienced no big shocks (except the more or less common financial and economic crisis), so there is no need to speculate about the meaning of SWD in authoritarian regimes (Chu \& Wu 2019) or the impact of extraordinary events to explain national developments.

We will first explore the mean scores for the three evaluations in both years: 1) do we find general patterns of nostalgia and of democratic optimism or pessimism? 2) how well are national samples able to remember and foresee their satisfaction with democracy (is there wisdom in the crowds?)? Secondly, we will briefly compare these judgments with changes in expert opinions about the quality of democracy and changes in the populist share of the vote. Thirdly, we move to the individual level and explore how the judgments are related to differences in political trust, feelings of efficacy and populist sympathies.

\section{Satisfaction with democracy in 2004 and 2014}

To introduce the data and answer our first 'accuracy'-question, Table 1 shows country level average scores for satisfaction with democracy today $(\mathrm{t})$, ten years ago ( $\mathrm{p}(\mathrm{ast}))$ and ten years from now (f(uture)) in 2014 and 2004 and some comparisons of these scores.

In 2014 citizens of 11 of the 17 countries indicated a lower average level of satisfaction with democracy than they thought they had ten years before, only the Polish people show a higher level (and in the other 5 countries there is no significant change; column 4). Ten years before, in 2004, citizens of 11 countries expected, on average, a decline in satisfaction and 6, on average, an increase (column 8). Comparing data from both years in the last two columns, we see that average satisfaction with democracy increased in 7 countries and decreased in 7 countries (and did not change in 3; column 9). Comparing the actual change in satisfaction with the perceived change in 2014, we see in column 10 that the perception of change was more negative than the real change in 11 countries and more positive in 5 (and unchanged in Austria). 
Table 1. Satisfaction with democracy today $(=\mathbf{t})$, ten years ago (past $=\mathbf{p}$ ) and ten years from now (future $=\mathbf{f})$ : mean scores $(0=$ very poorly, $10=$ very well) and differences; population 18 years and older

\begin{tabular}{|c|c|c|c|c|c|c|c|c|c|c|}
\hline & \multicolumn{4}{|c|}{2014} & \multicolumn{4}{|c|}{2004} & \multicolumn{2}{|c|}{$2014-2004$} \\
\hline & $\begin{array}{l}\stackrel{\ddot{D}}{\vec{\Delta}} \\
\text { }\end{array}$ & $\stackrel{N}{\stackrel{N}{D}}$ & $\begin{array}{l}\stackrel{\omega}{\ddot{D}} \\
\underset{\Phi}{D}\end{array}$ & 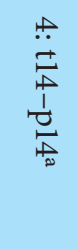 & 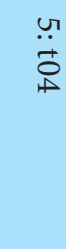 & $\begin{array}{l}\stackrel{8}{\circ} \\
\stackrel{\circ}{\circ}\end{array}$ & $\begin{array}{l}\stackrel{N}{\not} \\
\stackrel{\circ}{\$}\end{array}$ & 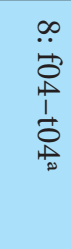 & 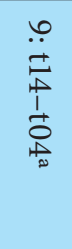 & 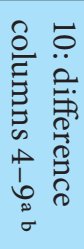 \\
\hline Austria (AT) & 6.4 & 7.0 & 5.5 & -0.7 & 7.1 & 7.6 & 6.5 & -0.6 & -0.7 & 0 \\
\hline Belgium (Flanders) (BE) & 5.6 & 5.8 & 5.1 & -0.2 & 5.4 & 5.5 & 5.0 & -0.4 & 0.2 & -0.4 \\
\hline Czech Republic (CZ) & 4.5 & 4.5 & 4.8 & -0.1 & 5.4 & 4.7 & 5.8 & 0.4 & -0.9 & 0.8 \\
\hline Denmark (DK) & 7.4 & 7.7 & 7.0 & -0.2 & 7.8 & 7.8 & 7.4 & -0.4 & -0.4 & 0.2 \\
\hline Finland (FI) & 6.4 & 6.6 & 6.0 & -0.2 & 6.7 & 6.3 & 6.3 & -0.4 & -0.3 & 0.1 \\
\hline France (FR) & 4.8 & 5.7 & 3.9 & -1.0 & 5.4 & 5.9 & 4.6 & -0.8 & -0.7 & -0.3 \\
\hline Germany (DE) & 6.6 & 6.7 & 6.2 & 0.0 & 5.6 & 6.5 & 5.0 & -0.6 & 1.0 & -1.0 \\
\hline Hungary (HU) & 4.9 & 5.3 & 5.7 & -0.5 & 4.9 & 4.5 & 6.3 & 1.4 & -0.1 & -0.4 \\
\hline Netherlands (NL) & 6.4 & 6.9 & 6.1 & -0.5 & 6.5 & 7.0 & 6.0 & -0.5 & -0.1 & -0.4 \\
\hline Norway (NO) & 7.6 & 7.6 & 7.1 & 0.0 & 6.7 & 7.0 & 6.1 & -0.6 & 0.9 & -0.9 \\
\hline Poland (PO) & 4.3 & 4.2 & 4.9 & 0.1 & 4.3 & 3.9 & 6.0 & 1.7 & 0.0 & 0.1 \\
\hline Slovak Republic (SK) & 4.7 & 4.7 & 5.0 & 0.0 & 4.1 & 4.1 & 5.0 & 0.9 & 0.6 & -0.6 \\
\hline Slovenia (SL) & 3.7 & 5.5 & 4.1 & -1.9 & 5.0 & 5.1 & 5.5 & 0.5 & -1.3 & -0.6 \\
\hline Spain (ES) & 4.4 & 5.6 & 4.8 & -1.2 & 6.1 & 5.5 & 6.6 & 0.5 & -1.7 & 0.5 \\
\hline Sweden (SE) & 7.1 & 7.4 & 6.8 & -0.3 & 6.4 & 7.0 & 5.7 & -0.7 & 0.7 & -1.0 \\
\hline Switzerland $(\mathrm{CH})$ & 7.6 & 7.8 & 7.1 & -0.1 & 6.9 & 7.3 & 6.2 & -0.7 & 0.7 & -0.8 \\
\hline United Kingdom (UK) & 6.3 & 6.4 & 5.9 & 0.0 & 6.1 & 6.2 & 5.6 & -0.5 & 0.2 & -0.2 \\
\hline
\end{tabular}

a Significant ( $\mathrm{p}<0,01$ two-sided;) differences and changes are marked bold (if positive also italic).

$\mathrm{b}$ Negative value $=$ perceived change more negative than actual change, positive value $=$ perceived change more positive than actual change.

Source: ISSP 2004 \& 2014

Thus, in most countries people are too negative about the changes in satisfaction, i.e., their retrospective evaluations of the working of democracy. Or put in other words, though 'satisfaction with democracy today' has increased in as many of our countries as decreased from 2004 to 2014 (column 9), citizens in all but one country (Poland), at the same time, believed in 2014 that their democracies have not improved over the last ten years (column 4). On first sight, this might be seen as evidence for the 'nostalgic' bias of retrospective questions (Smith, 1984, p. 646). However, it is at least not a universal phenomenon: 5 countries show the opposite bias in column 10 of Table 1 and there is not always a clear majority of people seeing a decline in satisfaction: indeed, 11 of 17 countries 
in 2014 (column 4) but in 2004 this was the case in 8 countries with 5 countries perceiving an improvement between 1994 and 2004. ${ }^{5}$

Before examining the possible relevance of the retrospective and prospective outlook for measuring satisfaction with democracy, let us let us first have another look at the relationship between actual and remembered satisfaction in 2004. We visualize it in Figure 1.

Figure 1. SWD in 2004: actual scores in 2004 and remembered scores in 2014

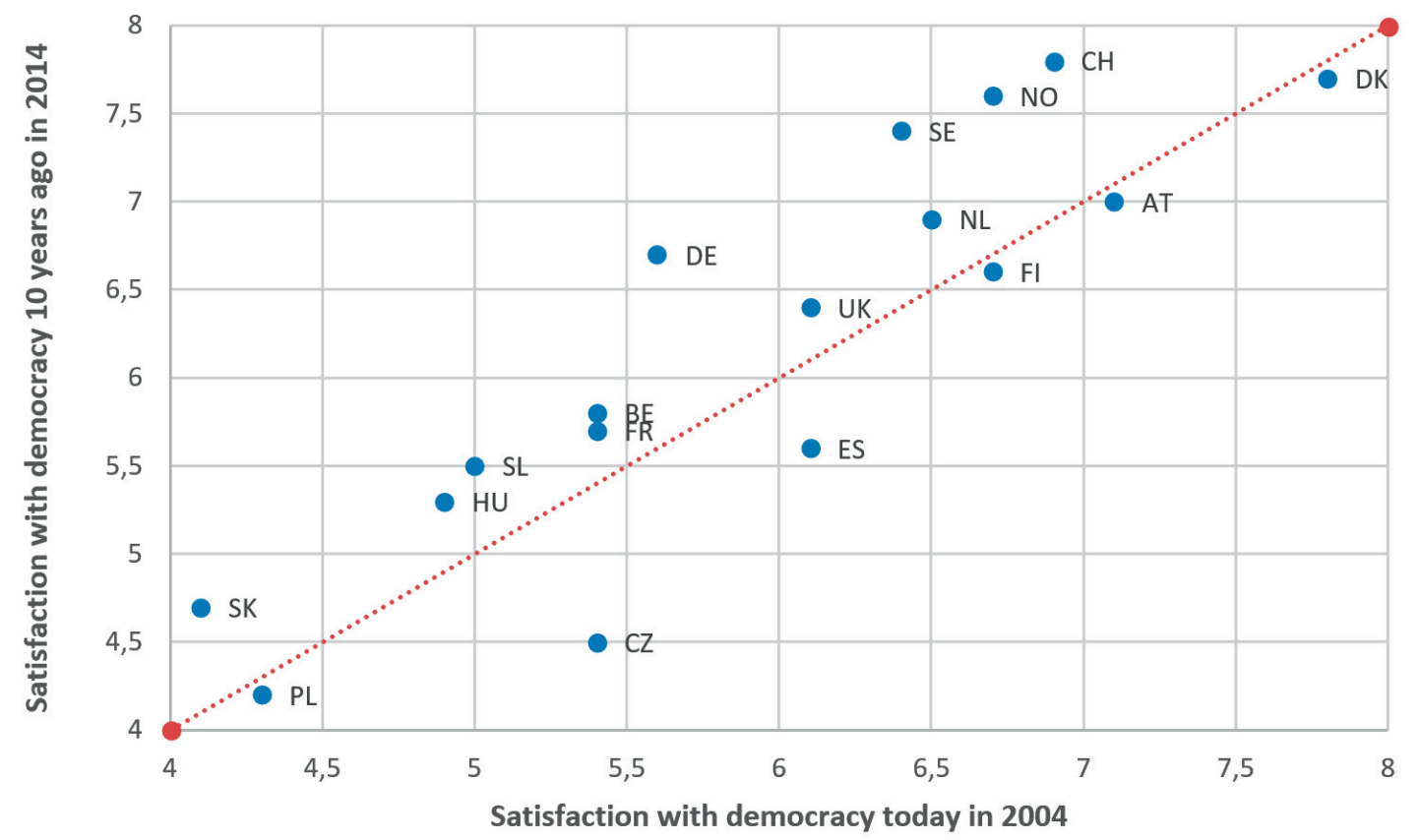

Source: ISSP 2004-2014

First and foremost, on average, retrospective validity at the aggregated country level appears to be reasonably good. The average absolute retrospective bias (positive or negative) per country is 0.3 points and the correlation between retrospective and actual satisfaction with democracy is 0.88 and slightly higher than when people would have filled in the same grade as they did for SWD today (0.80). The correlation between expected average satisfaction with democracy ten years from now in 2004 and actual satisfaction with democracy in 2014 however is only 0,33. In other words, while citizens, as a collective, are quite able to remember their past 'satisfaction with democracy' respondents are not able to predict their future satisfaction with democracy very well. So, if there is any 'wisdom of the crowds' (Surowiecki 2004), it is in knowing the past and not in foreseeing the future.

\section{The Polish exception}

In general, both the retrospective evaluation of democracy (over the past ten years) and the prospective expectation tend to be negative for most countries in 2014. Poland is the only country in our sample where citizens retrospectively believed in 2014 that, over the previous ten years (i.e., compared to 2004), democracy had improved. This is probably due

5 There was a net idea of progress in Poland in both years, in no other country in 2014 but in 2004 also in the Czech Republic, Finland, Hungary and Spain. 
to economic considerations. At the beginning of this century Poland was reconstructing its economy. Unemployment reached a record high (18.8\%) in February 2003 (Smeets and Warzynski, 2006). Polish respondents probably had these (severe) economic circumstances in mind when comparing satisfaction with democracy in 2014 with one's satisfaction with democracy ten years before in 2004, when the unemployment rate was about double that of 2014. This observation supports the accumulating evidence in the literature (Christmann, 2018) that satisfaction with democracy and economic performance are positively correlated and probably is also the main explanation for the (relatively) positive retrospective and prospective evaluations of democracy in Poland (and the few other Central and Eastern-European countries in our sample that have, since their transition from communism and their accession into the EU, seen their economies grow at a relatively fast pace).

\section{Central and Eastern Europe positive about the future of democracy}

Besides the positive retrospective evaluation of democracy in Poland we find it remarkable that the prospective evaluations of democracy, both in 2004 and 2014, were positive (or statistically not different from zero in the case of the Slovak Republic and Slovenia in 2014) for the five Central and Eastern European countries in our example (see table 1) while the same outlook was pessimistic in 2004 and 2014 for all the other Western European countries in our sample (with the exception of Spain). Apparently, the democratic mood in general and democratic expectations in particular tend to be more optimistic in the Central and Eastern European countries. Maybe their relatively recent admission to the EU can be a (part of the) explanation for this difference.

\section{Correlates of national changes}

Changes in 'satisfaction with democracy today' between 2004 and 2014 (column 4 in Table 1) suggest a balance of positive and negative changes of national democracies, the retrospective judgments of the 2014 respondents suggest negative developments and rising 'democratic discontent' in most countries over the same period. We take a look at two indicators that might support one or the other expectation, or neither of them.

\section{Citizens and experts}

The first are expert judgments. We use the 'Democracy Barometer' (Bühlmann e.a., 2015). The correlation of changes according to the overall 'quality of democracy' index of this barometer with changes in average 'satisfaction with democracy today' between 2004 and 2014 (column 9 in Table 1) is only 0,4. The correlation between changes on the index and perceived changes of the 2014 respondents (column 4 in Table 1) is also positive but even weaker $(0,24)$. Figure 2 shows the pattern. 
Figure 2. Changes 2004-2014 according to ISSP-respondents in 2014 and the 'democracy index' (20042014)

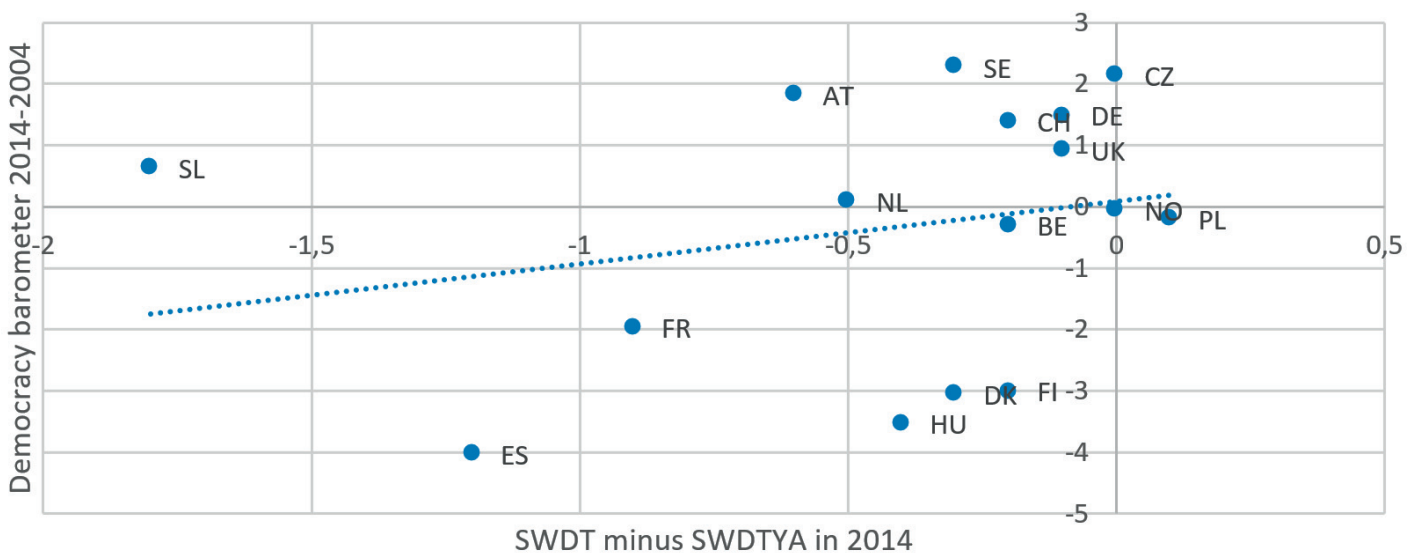

Sources: ISSP 2014 and Democracy Barometer (2004-2014)

We have also used the Economist Intelligence Unit's (The Economist Intelligence Unit, 2019) democracy index (available from 2006 on, so we are not able to compare exactly the same period). Both the retrospective outlook as well as the 'changes in average satisfaction with democracy today' between 2004 and 2014 correlate at a positive but weak level of 0,4 with the changes according to experts. The retrospective outlook therefore does not appear to provide us with any additional information in this respect compared to the commonly used 'satisfaction with democracy today' indicator.

\section{SWD-changes and populist vote}

One may assume a negative relationship between (changes in) satisfaction and populist vote, be it because dissatisfaction stimulates populist vote, or be it that growing populist vote makes (other) people dissatisfied.

Based on research conducted by Rooduijn and others (Rooduijn, e.a. 2019) ${ }^{6}$ the 'populist vote share' decreased in 3 of our 17 countries (namely Belgium, Norway, and Slovenia) between 2004 and 2014 and increased in the other 14. This increase corresponds with the overall (more) pessimistic retrospectively outlook during the same period and not with the overall stability of 'satisfaction with democracy today' in 2004 and 2014 (see Table 1). However, there is no correspondence of changes in the populist vote and changes of (retrospective) satisfaction at the national level.

To summarize, correlations at the national level for the retrospective outlook are in general weak and not stronger compared to changes in average 'satisfaction with democracy today' between 2004 and 2014. One might find a statistically significant relationship with a larger number of countries, but it is highly unlikely to find substantial relationships. But what about the individual level? Does the retrospective (has democracy improved or not during the past ten years?) or prospective (will democracy improve or not during the next

6 We would like to thank Matthijs Rooduijn for providing us with a dataset that categorizes for each country and or every election year which parties are 'populist', and which are not. We combined this dataset with the election results from 'Parlgov' to calculate the populist vote share. 
ten years?) outlook provide us with additional insights with regard to individual opinions and behavior?

\section{Correlations at the individual level}

So much about crowds and countries. In this third part we focus on individuals. First a look at attitudinal correlations of SWD in all 17 countries in 2014 and then, for one country, a further look at the relationship between measurements of dissatisfaction and the intention to vote on populist parties.

\section{Satisfaction with democracy and other attitudes towards politics}

How important are present scores, perceived changes, and expected developments in satisfaction with democracy for other attitudes towards the political system? ISSP has a few questions in this area and we summarize them as indicators for political efficacy or perceived political responsiveness ('People like me don't have any say about what the government does' and 'I don't think the government cares much what people like me think') and political trust ('Most of the time we can trust people in government to do what is right' and 'Most politicians are in politics only for what they can get out of it personally'). The reliability of both scales is rather low, but, with one exception, good enough for some exploratory analyses. ${ }^{7}$ How well are both scales predicted by an individual's 'satisfaction with democracy today', the retrospective evaluation how democracy has been developing during the past ten years and the prospective expectation how democracy will develop during the next ten years?

For political trust we find strong positive effects of SWD today in all 17 countries, in only four countries small significant $(\mathrm{p}<.05)$ effects of the experienced change in SWD (negative in $\mathrm{CZ}$, and SK, and positive in DE, and $\mathrm{HU}$ ). We get similar results for responsiveness: strong positive effects of SWD today in all 16 countries (France was left out) and four minor significant effects of perceived change in SWD (positive in AT, HU, and $\mathrm{PL}$, negative in SK). These results do not seem to indicate that retrospection is strongly correlated with political trust and responsiveness at the individual level. But what about expectations? Do respondents who expect democracy to improve in the years to come show higher levels of political responsiveness and political trust?

With three self-selecting regression analyses (stepwise, forward selection and backward elimination), we have looked for the best combination of predictor of political responsiveness and trust among the three SWD measurements and the two difference scores (today - past and future - today). The three different ways of selecting variables give identical results most of the time. Both political trust and perceived political responsiveness are first of all predicted by the expected SWD (in 14 of the 17/16 countries) and secondly in most countries by the SWD today or by the expected change. ${ }^{8}$ In other words, one's expected satisfaction with democracy ten years from now and whether or not that is an improvement compared to one's current satisfaction are important variables for predict-

7 Average value of Cronbach's alpha for the trust scale is .51 (lowest value .42) for the 17 countries, for the responsiveness scale .75 (lowest value .56) for 16 countries (France is excluded with a value of .09).

8 In most cases two variables are selected. Of course, there is multicollinearity between the five indicators, but for the selections the VIF values are between 1 and 10 . 
ing an individual's level of political trust and belief in the responsiveness. This is in line with Nadeau et al.(2019) who also concluded that individual expectations are an important predictor for democratic support. Optimism and pessimism color citizens' attitudes towards political institutions and democracy itself.

\section{Dissatisfaction and the populist vote in The Netherlands}

Finally, for one country, we have made a brief analysis to determine the possible additional value of the retrospective and prospective outlook in predicting the populist vote at the individual level. Again, the three (stepwise, forward, and backward) regression analyses point toward the same conclusion: besides 'satisfaction with democracy today' the expected change during the next ten years (the 'prospective outlook') is able to predict whether or not an individual will vote for a populist party in The Netherlands. The retrospective outlook does not provide extra information and is therefore not included in the regression analyses. The less satisfied one is with democracy today, and the more one is expecting this satisfaction to decrease during the next ten years, the greater the chance of voting for a populist party.

\section{Conclusions and discussion}

One would expect that a 'backward looking perspective' measured by an explicitly retrospective indicator might be crucial to measure 'democratic (dis)content' well, especially in an age of (populist) discontent that is associated with 'nostalgia' for a 'golden past' according to recent literature (Steenvoorden and Harteveld, 2018). We have delved into this question in this paper based on ISSP data, that have (as far as we could ascertain) not previously been used for this purpose. Our results are mixed. While on the one hand respondents are indeed able to estimate, as a collective, their past satisfaction with democracy quite accurately and, moreover, the, in general, rather pessimistic retrospective evaluation in 2014 is more than an expression of 'timeless nostalgia' (since the retrospective evaluation in 2004 was not as pessimistic) as some authors claim, these retrospective evaluations on the other hand do not correlate strongly and certainly not better at a national level with (changes in) expert opinions about the quality of democracy or changes in the share of the populist vote compared to changes in average satisfaction with democracy today between 2004 and 2014. However, at the individual level the prospective outlook does, as the most important determinant or on top of one's 'satisfaction with democracy today', help predict an individual's political trust and responsiveness as well as the chance that he or she might vote for a populist party. Therefore, to measure the mood in a society or predict voting behavior, or the level of political (dis)trust, it might be valuable to not only measure a respondent's 'satisfaction with democracy today' - as is conventionally done - but to also measure his or her expected satisfaction with democracy 'ten years from now'. These future expectations, we would like to argue, do matter, and by not only asking respondents about their 'satisfaction with democracy today' but also their expected 'satisfaction with democracy ten years from now', we are able to make a distinction between those who are optimistic and those who are pessimistic about the future of democracy irrespective of one's 'satisfaction with democracy today'. 
From our earlier research (Van Houwelingen, Dekker \& Den Ridder, 2012) we expected that the belief of democratic progress or decline (comparing SDW today with SDW 10 years ago) would have a stronger relationship with other attitudes to the political system, and to populist voting behavior, than the 'anchorless' (at least from a temporal perspective) SDW today judgement. We have found no evidence for this expectation. Nevertheless, we think research using the popular SWD today question could be enriched with information about how citizens see developments of the working of their democracy. Further research is needed, however, because it remains puzzling that the overall share of the populist vote in Europe has clearly risen between 2004 and 2014 (Rooduijn et al., 2019) while at the same time average 'satisfaction with democracy' has more or less remained constant i.e., increased and decreased for the same number of countries.

In an earlier panel study (Van Houwelingen, Dekker \& Den Ridder, 2012) we were able, as mentioned in the beginning, to discuss the paradox of stable judgments and, at the same time, predominantly negative pessimistic retrospective evaluations with respondents themselves. In general, they clearly indicated to prefer their own usually more pessimistic retrospective evaluations of democracy even though this was often not consistent with the 'grades' they had given for their current satisfaction throughout past surveys that implied a more positive retrospective evaluation. For example, a typical respondent could give the same grade each year for his satisfaction with politics at that moment but would at the same time indicate, retrospectively, that, nonetheless, 'politics was heading in the wrong direction last year'. If asked to choose between these two inconsistent evaluations, respondents would almost always choose for the more pessimistic retrospective evaluations. We have observed this paradox in other research as well. For example, when asked to retrospectively evaluate satisfaction with one's own life at this moment compared to one's (remembered) satisfaction 'ten years ago' respondents are inclined to give positive evaluations compared to the (slightly negative) trendlines for satisfaction with 'one's life' that we were able to construct based on (quarterly) longitudinal research during the same past ten years (Dekker \& Van Houwelingen, 2017). Apparently, respondents tend to evaluate, retrospectively, their own lives (more) optimistically while being retrospectively (more) pessimistic about society in general at the same time. These findings ask for further research to temporally anchor measurements of SDW and satisfaction with other aspects of social life.

\section{References}

Anderson, C. (2002). Good questions, dubious inferences, and bad solutions: Some further thoughts on satisfaction with democracy. Binghamton University. Binghamton.

Ariely, G. (2013). Public administration and citizen satisfaction with democracy: cross-national evidence International Review of Administrative Sciences 79(4), 747-766.

Beckett, M., Da Vanzo, J., Sastry, N., Panis, C., \& Peterson, C. (2001). The quality of retrospective data: An examination of long-term recall in a developing country. Journal of Human Resources, 36(3), 593-625.

Bühlmann, M, Heyne, L., Merkel, W., Müller, L., Ruth, S. and B. Weßels (2015). Democracy barometer: a new approach to evaluating the quality of democratic systems. Democratic Audit Blog (09 Apr 2015). www.democraticaudit.com 
Canache, D., Mondak, J., \& Seligson, M. (2001). Meaning and measurement in cross-national research on satisfaction with democracy. Public opinion quarterly, 65(4), 506-528.

Ceron, A., \& Memoli, V. (2016). Flames and debates: do social media affect satisfaction with democracy? Social Indicators Research, 126(1), 225-240.

Christmann, P. (2018). Economic performance, quality of democracy and satisfaction with democracy. Electoral Studies, 53, 79-89.

Chu, Y., \& Wu, C. (2019). Equality of opportunity and satisfaction with te political system. In: Park, C. \& Uslaner E. (eds), Inequality and Democratic Politics in East Asia. New York: Routledge.

Clarke, H., Dutt, N., \& Kornberg, A. (1993). The political economy of attitudes toward polity and society in Western European democracies. The Journal of Politics, 55(4), 998-1021.

Dahlberg, S., \& Holmberg, S. (2014). Democracy and bureaucracy: How their quality matters for popular satisfaction. West European Politics, 37(3), 515-537.

Dekker, P. \& Van Houwelingen, P. (2017). Burgerperspectieven 2017|4. The Hague: The Netherlands Institute for Social Research.

Finney, H. (1981). Improving the reliability of retrospective survey measures: Results of a longitudinal field survey. Evaluation Review, 5(2), 207-229.

Foa, R.S., Klassen, A., Slade, M., Rand, A. and R. Williams (2020). The Global Satisfaction with Democracy Report 2020. Cambridge, United Kingdom: Centre for the Future of Democracy.

Golden, B. (1992). The past is the past-or is it? The use of retrospective accounts as indicators of past strategy. Academy of Management journal, 35(4), 848-860.

Hochschild, A. (2016). Strangers in Their Own Land. Anger and Mourning on the American Right. New York: The New Press.

Kenny, M. (2017). Back to the populist future?: understanding nostalgia in contemporary political discourse. Journal of Political Ideologies, 22(3), 256-273.

Kilpatrick, F. P., \& Cantril, H. (1960). Self-anchoring scaling: A measure of individuals' unique reality worlds. Journal of Individual Psychology, 16, 158-173.

Lacy, D. \& Christenson, D. (2017). Who Votes for The Future? Information, Expectations and Endogeneity in Economic Voting. Political Behavior, 39, p. 347-375.

Lagos, M. (2003). Support for and Satisfaction with Democracy. International Journal of Public Opinion Research, 15(4), 471-487.

Linde, J., \& Ekman, J. (2003). Satisfaction with democracy: A note on a frequently used indicator in comparative politics. European journal of political research, 42(3), 391-408.

Morlino, L., \& Quaranta, M. (2014). The non-procedural determinants of responsiveness. West European Politics, 37(2), 331-360.

Nadeau, R., V. Arel-Bundock \& J. Daoust (2019). Satisfaction with Democracy and the American Dream. The Journal of Politics, 81(3), 1080-1084.

Norris, P. (1999). Critical Citizens: Global Support for Democratic Government. Oxford: Oxford University Press.

Norris, P., \& R. Inglehart (2019). Cultural Backlash: Trump, Brexit, and Authoritarian Populism. Cambridge: Cambridge University Press.

Pammett, J. (ed.) (2016). ISSP 2014-Citizenship II: Questionnaire development report. Cologne: Gesis (https://dbk.gesis.org/dbksearch/download.asp?db=E\&id=59917). 
Quaranta, M. (2018). How citizens evaluate democracy: an assessment using the European Social Survey. European Political Science Review, 10(2), 191-217.

Rooduijn, M., Van Kessel, S., Froio, C., Pirro, A., De Lange, S., Halikiopoulou, D., Lewis, P., Mudde, C. \& Taggart, P. (2019). The PopuList: An Overview of Populist, Far Right, Far Left and Eurosceptic Parties in Europe (http://www.popu-list.org).

Schwarz, N., \& Oyserman, D. (2001). Asking questions about behavior: Cognition, communication, and questionnaire construction. American Journal of Evaluation, 22(2), $127-160$.

Smeets, V., \& Warzynski, F. (2006). Job creation, job destruction and voting behavior in Poland. European Journal of Political Economy, 22(2), 503-519.

Smith, T. (1984). Recalling attitudes: An analysis of retrospective questions on the 1982 GSS. Public opinion quarterly, 48(3), 639-649.

Steenvoorden, E., \& Harteveld, E. (2018). The appeal of nostalgia: the influence of societal pessimism on support for populist radical right parties. West European Politics, 41:1, $28-52$.

Taggart, P. (2000). Populism. Buckingham: Open University Press.

The Economist Intelligence Unit (2019). Democracy Index 2019. London: EIU.

Van Houwelingen, P., Dekker, P. \& J. den Ridder (2012). Oordelen over de samenleving: tussen gewenning en gouden gloed. Paper presented at Sociologendagen 2012, Utrecht 24 May 2012.

Van der Meer, T., \& Dekker, P. (2011). Trustworthy states, trusting citizens? A multilevel study into objective and subjective determinants of political trust. In: S. Zmerliand \& M. Hooghe (eds). Political trust: Why context matters, Colchester: ECPR Press, pp. 95-116.

Van der Meer, T., \& Hakhverdian, A. (2017). Political Trust as the Evaluation of Process and Performance: A Cross-National Study of 42 European Countries. Political Studies, 65(1), 81-102.

Van Elsas, E., Lubbe, R., Van der Meer, T., \& Van der Brug, W. (2013). Vote recall: A panel study on the mechanisms that explain vote recall inconsistency. International Journal of Public Opinion Research, 26(1), 18-40. 